\title{
Carbonic Anhydrase IV Expression in Rat and Human Gastrointestinal Tract Regional, Cellular, and Subcellular Localization
}

\author{
Robert E. Fleming, ${ }^{\star}$ Seppo Parkkila, ${ }^{\ddagger}$ Anna-Kaisa Parkkila, ${ }^{\ddagger}$ Hannu Rajaniemi, ${ }^{\ddagger}$ Abdul Waheed, ${ }^{\mathbf{s}}$ and William S. Sly \\ *Department of Pediatrics and Pediatric Research Institute, St. Louis University School of Medicine, St. Louis, Missouri 63104; \\ ${ }^{\ddagger}$ University of Oulu, Department of Anatomy, Oulu, Finland; and ${ }^{8}$ Edward A. Doisy Department of Biochemistry and Molecular Biology, \\ St. Louis University School of Medicine, St. Louis, Missouri 63104
}

\begin{abstract}
Carbonic anhydrase IV (CA IV) is a glycosylphosphatidylinositol-linked isozyme previously identified on the surface of renal tubular epithelium and certain populations of vascular endothelium. This report identifies the regional, cellular, and subcellular localization of CA IV in the rat gut. Northern blot and RT-PCR analyses demonstrated little CA IV expression in stomach or proximal small intestine, but abundant expression in distal small and large intestine. In contrast, CA II mRNA was abundant in stomach, decreased in proximal small intestine, low in distal small intestine, and abundant in large intestine. CA I mRNA was detected only in large intestine. The regional distribution of CA IV activity correlated with distribution of CA IV mRNA. Immunohistochemistry localized CA IV to the apical plasma membrane of the mucosal epithelium in distal small intestine and large intestine. Signal intensity was greatest in colon. CA IV was additionally found in submucosal capillary endothelium of all gastrointestinal regions. Immunohistochemical findings in human stomach and colon paralleled those in the rat. These studies demonstrate pre-translational isozyme-specific regulation of $\mathrm{CA}$ expression along the cranial-caudal axis of the gastrointestinal tract. The regional, cellular, and subcellular localizations are consistent with participation of CA IV in the extensive ion and fluid transport in the distal small and large intestine. (J. Clin. Invest. 1995. 96:29072913.) Key words: bicarbonate • brush borders • ion transport $\cdot$ glycosylphosphatidylinositol linkage $\cdot$ colon
\end{abstract}

\section{Introduction}

The carbonic anhydrases are zinc-containing metalloenzymes which catalyze the hydration of carbon dioxide and dehydration of carbonic acid. In terrestrial vertebrates, seven carbonic anhydrase $(\mathrm{CA})^{1}$ isozymes have been identified. While homologous

Address correspondence to William S. Sly, Edward A. Doisy Department of Biochemistry and Molecular Biology, St: Louis University School of Medicine, 1402 S. Grand Blvd., St. Louis, MO 63104. Phone: 314-577-8131; FAX: 314-776-1183.

Received for publication 26 July 1994 and accepted in revised form 21 August 1995.

1. Abbreviations used in this paper: CA, carbonic anhydrase; RT, reverse transcription.

J. Clin. Invest.

(C) The American Society for Clinical Investigation, Inc.

0021-9738/95/12/2907/07 \$2.00

Volume 96, December 1995, 2907-2913 in amino acid sequence, the isozymes differ in catalytic activities and sensitivities to inhibitors. They also differ in their tissue distributions and subcellular localizations; CA I, II, III, and VII are cytoplasmic, CA VI is secretory, CA V mitochondrial, and CA IV membrane-associated (1-6).

One of the more recently characterized isozymes is the membrane-associated carbonic anhydrase, CA IV. This isozyme, anchored to the cell membrane by a glycophosphatidylinositol glycan linkage, has been purified from kidney and lung tissue of several mammalian species (7-9). CA IV in kidney is expressed primarily on the apical surface of the renal tubular epithelium. In lung, the enzyme is expressed intensely on the luminal surface of the alveolar capillary endothelium (10). CA IV is also expressed on the endothelial cell surface of other microcapillary beds including the choriocapillaris of the human eye (11), cortical capillaries of mouse and rat brain (12), and the capillary membranes which sediment with sarcolemmal vesicles from rat skeletal muscle (13).

Prior studies on the tissue distribution of CA IV demonstrated CA IV mRNA in rat colon, at levels even greater than those found in lung, kidney, or brain (10). It has been long recognized that carbonic anhydrases play a role in ion and water transport in the distal small intestine and large intestine. While histochemical studies suggested that some of the carbonic anhydrase activity in the gut was membrane-associated, immunohistochemical or molecular reagents to identify CA IV expression were previously unavailable. Here we present Northern blot data which characterize the regional distribution of CA IV in rat gastrointestinal tract in comparison with other CA isozymes known to be expressed in the gut. We identify the cellular localization of CA IV in the rat gastrointestinal tract and demonstrate that CA IV is an abundant brush border enzyme in the lower gastrointestinal tract of both rat and human.

\section{Methods}

CA activity assay. Adult female Sprague-Dawley rats were anesthetized with intraperitoneal sodium pentobarbital, the left ventricle catheterized, the right atrium cut, and the systemic circulation perfused with normal saline until visually clear. Segments of gastrointestinal tract were dissected, rinsed in phosphate-buffered saline, and homogenized in 2 volumes of $25 \mathrm{mM}^{\text {TrisSO }}{ }_{4}, 1 \mathrm{mM}$ PMSP, $1 \mathrm{mM}$ benzamidine, and $1 \mathrm{mM}$ $o$-phenanthroline using a Brinkman homogenizer. Protein concentration was determined by modified Lowry's procedure (14). Carbon dioxide hydrase activity was determined using the method of Maren (15) as described (16), using $1 \mathrm{mg}$ of tissue homogenate protein. CA IV activity was determined by residual activity after incubation of cell extracts with $0.2 \%$ SDS at room temperature for $30^{\prime}$ (7). Activity assays were performed in duplicate and the average value reported.

Antisera. Polyclonal antisera to human CA IV and rat CA IV were produced and characterized by Zhu and Sly (3) and Waheed et al. (9). Normal rabbit serum was used in control stainings. The anti-CA IV sera 
showed no cross reactivity with CA I, II, or VI at the dilutions used in immunoblottings $(3,17)$.

Preparation of tissues. Adult Sprague-Dawley female rats were anesthetized with ether and sacrificed by decapitation. Tissue sections from the alimentary tract were immersion-fixed in 5\% paraformaldehyde in PBS for $18 \mathrm{~h}$ at $4^{\circ} \mathrm{C}$. Specimens were then frozen in liquid nitrogen and stored at $-80^{\circ} \mathrm{C}$. Frozen sections (Cryo-Cut Microtome, American Optical Corporation, Buffalo, NY) of $8 \mu \mathrm{m}$ were used for immunofluorescence staining.

Samples of human colon were obtained alongside routine histopathological specimens during surgical operations carried out at Oulu University Hospital. Tissue samples were divided into $5 \mathrm{~mm}$ pieces, fixed in Bouin's fluid (saturated aqueous picric acid/36-40\% formaldehyde/ glacial acetic acid 15:5:1) for $18 \mathrm{~h}$, or in $4 \%$ paraformaldehyde in 0.1 $\mathrm{M}$ phosphate-buffered saline (PBS) for $18 \mathrm{~h}$ at $4^{\circ} \mathrm{C}$. Samples were dehydrated and embedded in paraffin in a vacuum oven at $58^{\circ} \mathrm{C} .5 \mu \mathrm{m}$ sections were placed onto gelatin-coated microscope slides.

RNA isolation and analysis. RNA was isolated from snap-frozen tissues following dissolution in RNA-Stat-60 (TelTest, Inc., Friendswood, TX), according to the manufacturer's instructions and quantified by absorbance at $260 \AA .15 \mu \mathrm{g}$ of total cellular RNA was denatured in formaldehyde-containing buffer and electrophoresed in $1 \%$ agarose, $2.2 \mathrm{M}$ formaldehyde gels. Gels were stained with ethidium bromide to verify equivalent loading of intact RNA. The RNA was transferred to nylon membranes and hybridized with ${ }^{32} \mathrm{P}$-labeled cDNAs for rat CA IV (10), rat CA II (18), or murine CA I (19). Hybridization was performed at $60^{\circ} \mathrm{C}$ in Quickhyb (Stratagene) for $18 \mathrm{~h}$. The blots were washed in $2 \times \mathrm{SSC} / 0.1 \%$ SDS $15^{\prime}$ at RT twice, and in $0.1 \times \mathrm{SSC} /$ $0.1 \%$ SDS for $30^{\prime}$ at $60^{\circ} \mathrm{C}$. Some blots were reprobed after removal of signal by boiling in $0.1 \times$ SSC/0.1\% SDS for $30^{\prime}$. RT-PCR analysis of CA IV mRNA content was performed as follows. $10 \mu \mathrm{g}$ of total RNA from each gut segment were utilized in a reverse transcriptase reaction primed with oligo dT. One-tenth of the product was used in an amplification reaction using oligonucleotides corresponding to nucleotides 252-272 of the CA IV cDNA (10) as the forward primer and nucleotides $470-491$ as the reverse primer. The amplification reactions consisted of 30 cycles of $94^{\circ} \mathrm{C}$ for $1^{\prime}, 55^{\circ} \mathrm{C}$ for $1^{\prime}$, and $72^{\circ} \mathrm{C}$ for $1^{\prime}$. The products were analyzed on a $1 \%$ agarose gel with size markers.

Immunohistochemistry. Immunoperoxidase and immunofluorescence was performed as follows. For immunoperoxidase staining, deparaffinized tissue sections were pretreated with $3 \% \mathrm{H}_{2} \mathrm{O}_{2}$ for $5^{\prime}$, washed with PBS for $5^{\prime}$ and pretreated with undiluted swine serum for $50^{\prime}$. Sections were rinsed with PBS and incubated with 1:100 diluted primary rabbit antiserum in $1 \%$ bovine serum albumin (BSA)-PBS for $1 \mathrm{~h}$. The sections were washed three times with PBS for $10^{\prime}$ each, treated again with swine serum for $40^{\prime}$, and incubated with biotinylated affinitypurified swine anti-rabbit immunoglobulins (Dakopatts, Copenhagen, Denmark) at 1:300 dilution in 1\% BSA-PBS for $1 \mathrm{~h}$. The tissue sections were washed three times with PBS for $10^{\prime}$ each and treated with swine serum for $5^{\prime}$ followed with 1:600 dilution of peroxidase-conjugated strepavidin in PBS for $30^{\prime}$. The tissue sections were washed three times with PBS for 5' each and incubated with $9 \mathrm{mg}$ 3,3'-diaminiobenzidine tetrahydrochloride (Fluka, Buchs, Switzerland) in $15 \mathrm{ml}$ PBS plus 10 microliters of $30 \% \mathrm{H}_{2} \mathrm{O}_{2}$. All incubations and washes were performed at room temperature and the sections mounted in Permount (Fisher Scientific, Fair Lawn, NJ).

Frozen sections of rat tissues were stained for CA IV using immunofluorescence. Sections were treated with undiluted swine serum for $40^{\prime}$ and rinsed with PBS. Washed tissue sections were incubated with primary rabbit antiserum at 1:100 dilution in 1\% BSA-PBS for $1 \mathrm{hr}$. The tissue sections were washed three times with PBS for $10^{\prime}$ each and incubated with 1:50 diluted rhodamine-conjugated swine anti-rabbit IgG (Dakopatts) in 1\% BSA-PBS for $1 \mathrm{~h}$. The tissue sections were washed three times with PBS for 5' each and finally mounted in Mowiol (Hoechst, Frankfurt, Germany). The tissue sections were viewed with conventional light and epifluorescence microscopes (Leitz, Aristoplan, Wetzlar, Germany) and a confocal laser scanning microscope (Leitz CLSM, Leica Laser Technics, Heidelberg, Germany) using an argon-
CAI

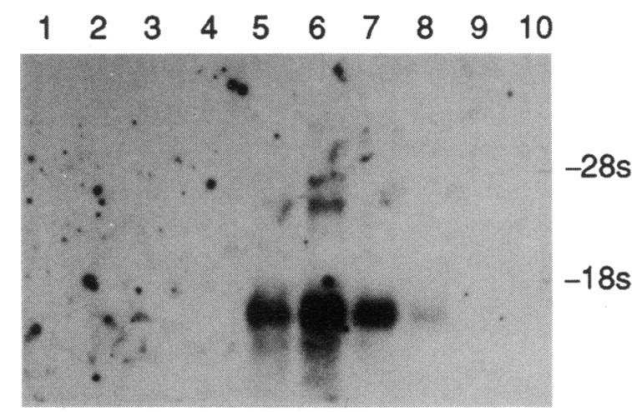

CA II

$\begin{array}{llllllllll}1 & 2 & 3 & 4 & 5 & 6 & 7 & 8 & 9 & 10\end{array}$

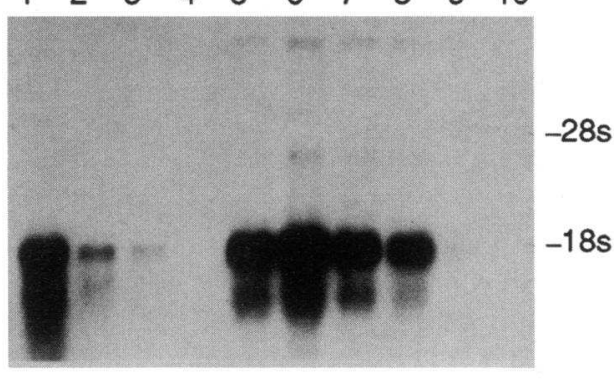

CA IV

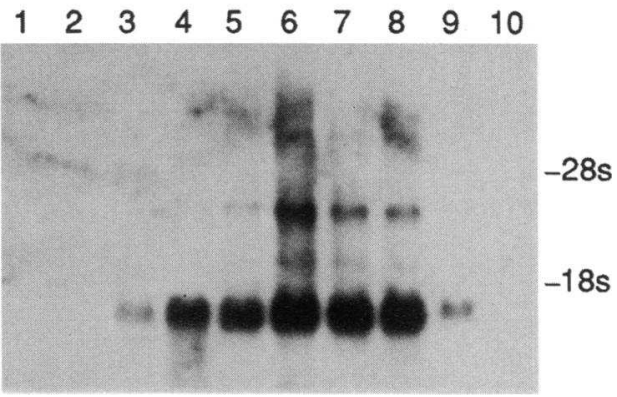

Figure 1. Regional distribution of CA I, CA II, and CA IV in the gastrointestinal tract of the adult rat. Total cellular RNA was isolated from the sources below. 15 grams was electrophoresed and blotted in parallel $\times 3$, and hybridized with ${ }^{32} \mathrm{P}$-labeled cDNA probes for murine CA I, rat CA II, or rat CA IV. The blots were washed and autoradiography performed for $24 \mathrm{~h}$ (CA I) or $18 \mathrm{~h}$ (CA II and CA IV). Lane 1, stomach; lane 2, duodenum; lane 3, jejunum; lane 4, ileum; lane 5 , cecum; lane 6 , proximal colon; lane 7 , mid colon; lane 8 , distal colon; lane 9, lung; lane 10 , liver.

krypton laser (75 $\mathrm{mW}$ output). The specimens were excited with a laser beam at $568 \mathrm{~nm}$ and the emission light focused through a pinhole aperture. The full field was scanned in square image formats of 512 $\times 512$ pixels, and the confocal images reconstructed using included software.

\section{Results}

Distribution of CA IV gene expression along the rat gastrointestinal tract. To characterize the relative distribution of CA IV expression along the rat gastrointestinal tract, RNA blot analysis was performed on gut segments from stomach to descending colon. As demonstrated in Fig. 1 (bottom), the 1.2-kb transcript corresponding to rat CA IV was found to be abundantly expressed throughout the large intestine. (A second transcript of $\sim 3 \mathrm{~kb}$ also detected under these conditions was not characterized further.) Expression of CA IV in the large intestine was found to be much higher than in lung tissue, from which this enzyme was first purified (7), or kidney tissue (data not shown). 
A. Total CA

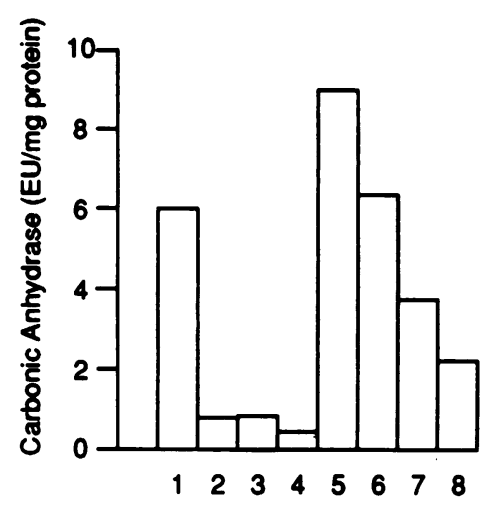

B. CA IV

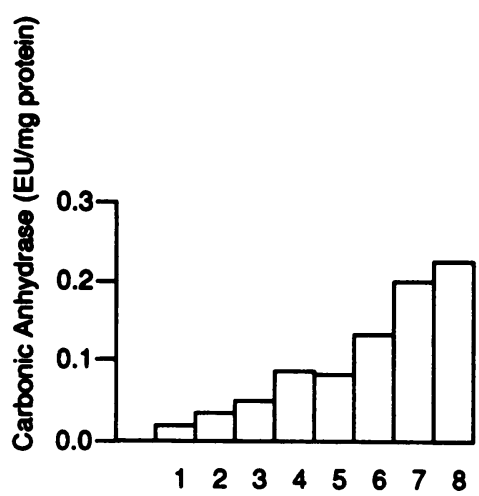

C. \% CA IV of Total CA

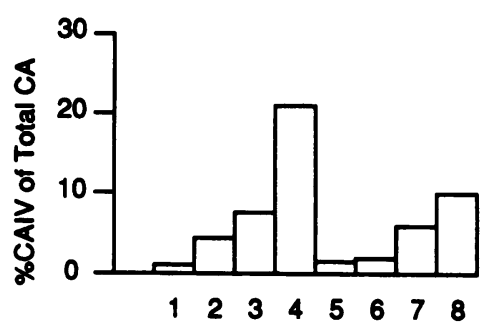

Figure 2. Distribution of CA IV activity in the rat gastrointestinal tract. Total CA activity $(A)$ and SDS-resistant CA activity $(B)$ were measured in homogenates of the following rat gut segments: (1) stomach, (2) duodenum, (3) jejunum, (4) ileum, (5) cecum, (6) proximal colon, (7) mid colon, and (8) distal colon. The contribution of CA IV to total CA activity in each region was calculated and presented as percent of total activity (C).

No CA IV expression was detected in stomach or duodenum by RNA blot analysis. However, in small intestine, increasing CA IV expression was found distally, with very abundant expression in ileum. This distribution of CA IV mRNA contrasted with that of the CA II isozyme (Fig. 1, middle). CA II was highly expressed in stomach, with decreasing levels distally in the small intestine. No signal for CA II was detected in ileum. In large intestine, however, CA II was abundantly expressed. CA II mRNA content was highest in the ascending colon, and somewhat decreased in the distal colon. Unlike CA II, the CA I isozyme was not expressed in stomach (Fig. 1, top). CA I mRNA was confined to the large intestine, with highest levels found in the ascending colon. Expression of CA I diminished markedly in the descending colon. These regional patterns demonstrate striking isozyme-specific regulation of CA gene expression along the cranial-caudal axis of the gastrointestinal tract.

Regional distribution of CA IV activity along the rat gastrointestinal tract. To determine if regions of the gastrointestinal tract demonstrating CA IV mRNA correlated with regions of CA IV activity, segments of perfused rat gut were homogenized and assayed. Total CA activity was measured, and CA IV activity determined as residual activity after incubation with SDS. Total CA activity was found to be highest in rat stomach and large intestine (Fig. $2 A$ ). Much lower activity was found in small intestine. In contrast, SDS-resistant CA activity (CA IV) was found to increase severalfold from the proximal small intestine to colon (Fig. $2 \mathrm{~B}$ ). CA IV made the greatest contribution to total CA activity in ileum, followed by distal colon (Fig. 2 C). Some CA IV activity was detected in all regions of the gut-even regions (stomach, duodenum) without detectable message by Northern blot. Analysis of these regions by RTPCR demonstrated the presence of CA IV transcripts, but at lower levels than regions where mRNA was detectable by Northern blot (data reviewed but not shown). Presumably the transcripts reflect expression of CA IV on endothelial capillaries in these regions (see below).

Immunohistochemical analysis of CA IV expression in rat gastrointestinal tract. To determine the cell types responsible for CA IV expression in the lower alimentary tract, immunohistochemical analysis was performed. Sections of rat colon (Fig. $3, A$ and $B$ ) and cecum (Fig. 3, $B$ and $E$ ) were reacted with antisera to rat CA IV and the immunofluorescent signal analyzed by confocal laser scanning microscopy and conventional epifluorescence microscopy. The apical plasma membranes of the nongoblet epithelial cells were found to stain intensely throughout the large intestine. Additional staining was seen in the subepithelial capillary endothelium, but absent from goblet cells, the muscularis, and serosa. No signal was obtained utilizing nonimmune rabbit serum in place of CA IV antisera (Fig. $3, C$ and $F$ ). Analysis of multiple segments from cecum to descending colon demonstrated no change in intensity or cellular distribution of CA IV throughout these segments (data not shown).

Immunohistochemical analysis of the cellular and subcellular distribution of CA IV was also performed on rat stomach and small intestine (Fig. 4). Epithelial staining was absent from sections of stomach and duodenum. Only the subepithelial capillary endothelium was positive in these segments (Fig. 4, $A$ and $B)$. Sections of jejunum, however, demonstrated weak staining of the apical plasma membrane of the nongoblet epithelial cells (Fig. 4 C). This epithelial staining was more intense in sections of ileum (Fig. $4 \mathrm{D}$ ). All regions of the gastrointestinal tract demonstrated signal in the subepithelial capillaries.

Immunohistochemical analysis of $C A I V$ in human colon. To determine if the abundant CA IV expression observed on the brush border epithelium of the rat large intestine is relevant to human biology, immunohistochemistry was performed on a section of human colon. As in the rat, a strong signal corresponding to CA IV was seen at the apical (luminal) surface of colon epithelium (Fig. $5 \mathrm{~B}$ ). Immunostaining was absent from goblet cells. As in the rat, subepithelial capillary endothelium also demonstrated positive staining. Signal from human stomach was confined to the capillary endothelial cell population, and absent from the epithelium, in agreement with findings in the rat (Fig. $5 \mathrm{~A}$ ). No signal was obtained using nonimmune serum in place of CA IV antisera (Fig. 5 C).

\section{Discussion}

Carbonic anhydrase activity has long been recognized to participate in the regional control of luminal $\mathrm{pH}$ and ion transport in the gastrointestinal tract. The striking regional differences in 

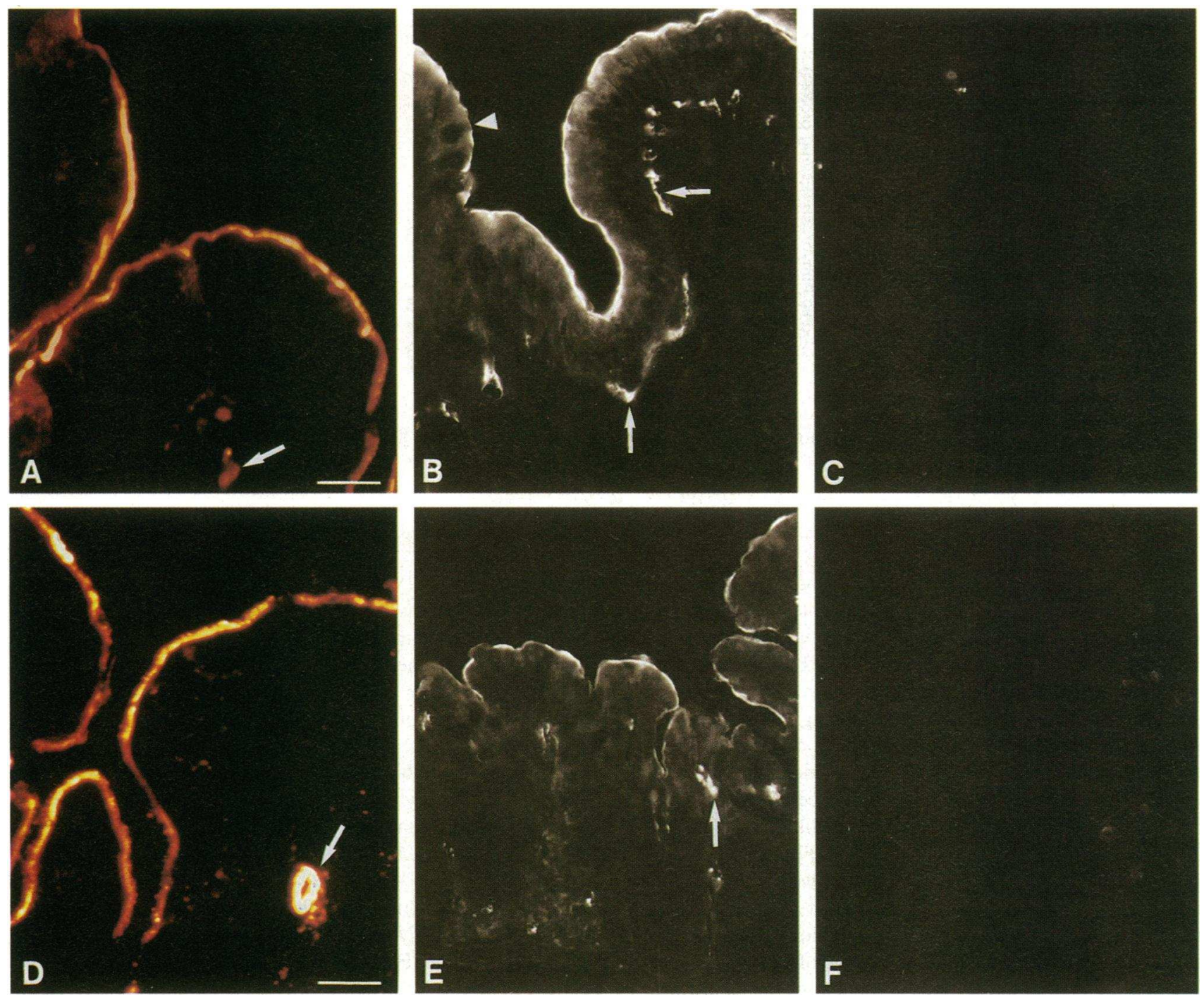

Figure 3. Immunohistochemical stainings of CA IV in the rat colon $(A, B)$ and cecum $(D, E)$. Both confocal laser scanning microscopy $(\mathrm{A}, \mathrm{D})$ and conventional epifluorescence microscopy $(B, E)$ reveal intense staining in the apical plasma membrane of the nongoblet epithelial cells. The goblet cells (arrowhead) show no specific staining. The subepithelial capillary endothelium (arrows) also shows positive immunofluorescence staining. Control sections of the colon $(C)$ and cecum $(F)$ showed no positive immunostaining when normal rabbit serum was used. Original magnifications: $\times 360(B, C, E$, and $F)$. Bars: $(A$ and $D) 10 \mu \mathrm{m}$. Pinholes 100/128 $(A / B), 679 / 772 \mathrm{~V}$, offsets $-58 /-67$.

CA activity along the cranial-caudal axis suggest important regulatory roles for $\mathrm{CA}$ in these processes. Stomach and colon have by far the highest total CA activity per unit of tissue protein. Jejunum has intermediate activity, and ileum low activity. The contribution of the cytosolic CAs to gastrointestinal CA activity is well established. Regions of the rat gut with highest CA activity demonstrate strong signals for CA I and/or CA II by immunohistochemistry (20). CA II is the dominant, if not only, cytosolic isozyme in the stomach of rats, humans, and most mammals (although CA I is present in the rumen epithelium of some ruminants). In rat colon, CA I and II are both present and contribute about equally to total activity. In addition to cytosolic CA activity, histochemical studies of the rat gut have demonstrated membrane-associated CA activity in several regions (20). Membrane-associated CA activity has also been detected in isolated membranous vesicles from rabbit ileum (21). This membrane-associated CA activity was speculated to represent CA IV, but not characterized further. By taking advantage of the resistance of the CA IV isozyme to denaturation by SDS, we were able to measure the contribution of CA IV to total CA activity in different regions of the rat gastrointestinal tract. While CA IV activity was detectable throughout the gut, activity was highest in the distal small and the large intestine. Because cytosolic CA activity is low in the distal small intestine, CA IV was found to make the greatest contribution to total CA activity in the ileum. Using molecular and immunologic probes specific to CA IV, we characterized expression of membrane-associated CA in the gastrointestinal tract further.

The distribution of CA IV mRNA along the gastrointestinal tract was found to correlate with distribution of CA IV activity. The pattern of intestinal CA IV mRNA content was found to be quite distinct from that of the cytosolic CAs. CA IV gene expression increased moving distally along the small intestine, while CA II decreased. CA I gene expression was undetectable in small intestine. All three CA isozymes (CA I, II, and IV) were 

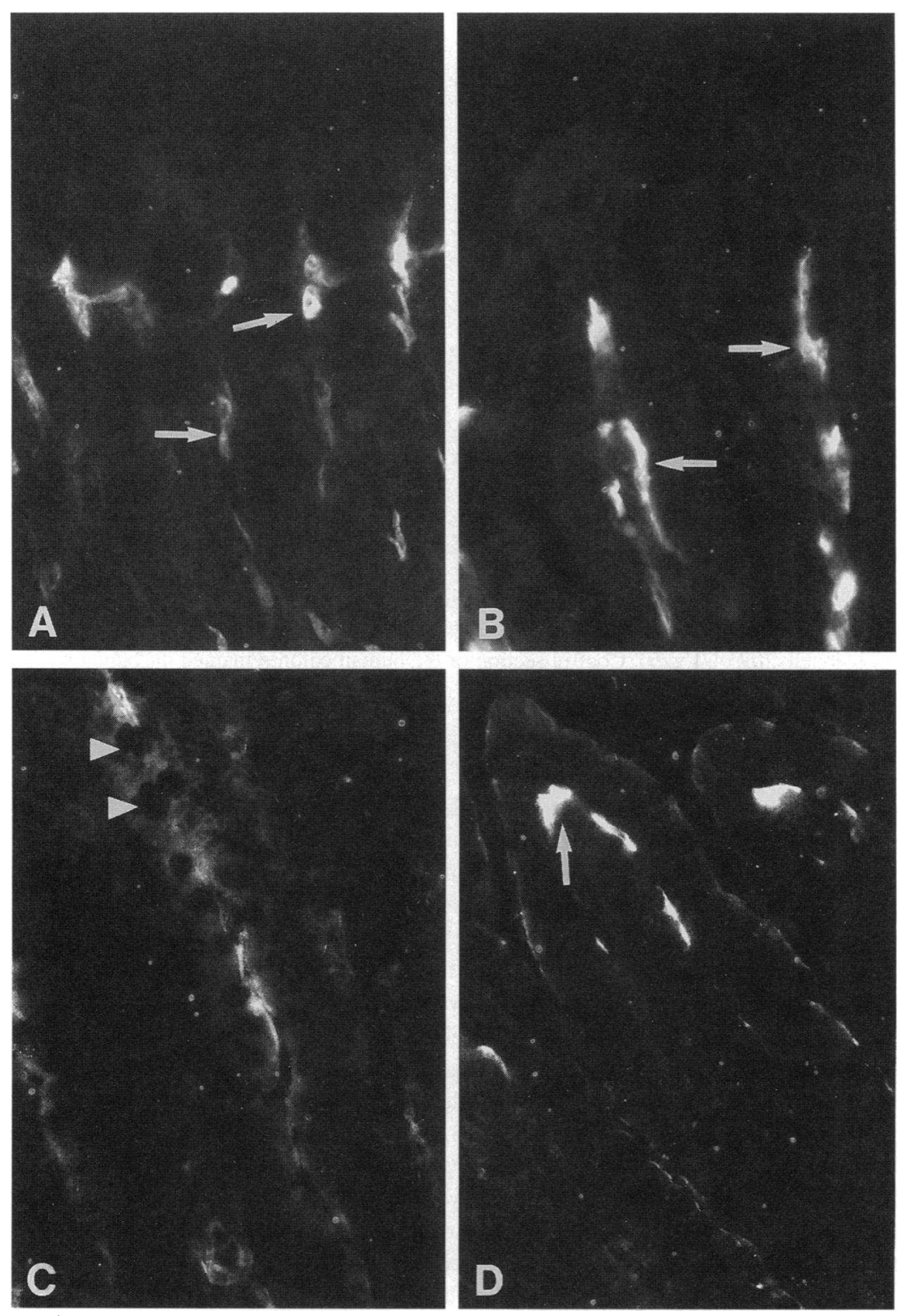

Figure 4. Immunohistochemical demonstration of CA IV in the rat stomach $(A)$, duodenum $(B)$, jejunum $(C)$, and ileum $(D)$. In the stomach and duodenum, only the subepithelial capillary endothelium (arrows) shows positive immunostaining. A faint positive staining is present in the apical plasma membrane of the nongoblet epithelial cells in the jejunum, which is somewhat more prominent in ileum. No staining is present in the goblet cells (arrowheads). Original magnifications $\times 360$.

found to be abundantly expressed in colon; however, differences among the isozymes were observed in different segments. Expression of the cytosolic CAs, especially CA I, diminished in the distal colon while expression of CA IV remained constant. These studies demonstrate isozyme-specific pretranslational regulation of CA expression in the gastrointestinal tract. Intestinal expression of CA I is directed by a colon-specific promoter (22). The molecular bases for expression of CA II and IV in the intestine are unknown.

Immunohistochemically, CA IV was found to localize in the distal small and the large intestine to the apical (luminal) side of the epithelial plasma membranes. The regional distribution of CA IV in the epithelium correlated with regional distribution of CA IV mRNA and activity. The regional, cellular, and subcellular localizations of CA IV in the gut epithelium are consistent with proposed physiologic roles for gastrointestinal CA. Carbonic anhydrase activity participates in ion and water transport in both the ileum and large intestine. Turnberg et al. (23) observed that the CA inhibitor acetazolamide markedly decreased both sodium and chloride absorption in human ileum. They proposed that much of the ileal ion absorption was mediated by electroneutral $\mathrm{Na}^{+} / \mathrm{H}^{+}$and $\mathrm{Cl}^{-} / \mathrm{HCO}_{3}^{-}$exchange, and concluded that $\mathrm{H}^{+}$and $\mathrm{HCO}_{3}^{-}$were derived from $\mathrm{CO}_{2}$ and $\mathrm{H}_{2} \mathrm{O}$ in a CA-catalyzed reaction in the ileal epithelium. Similar results have been reported in isolated segments of rat colon $(24,25,26)$. It has been further established that $\mathrm{CO}_{2}$ stimulates sodium and chloride absorption against a concentration gradient in the colon, and that this stimulation is blocked by CA inhibition $(24,25,26)$. It has been suggested that this stimulation depends on the catalyzed conversion of absorbed $\mathrm{CO}_{2}$ to $\mathrm{HCO}_{3}^{-}$and $\mathrm{H}^{+}$, which in turn use $\mathrm{Na}^{+}$I $\mathrm{H}^{+}$and $\mathrm{HCO}_{3}^{-} / \mathrm{Cl}^{-}$exchangers to effect sodium and chloride absorption. Because water passively follows ion movements in ileum and colon, CA activity impacts on water absorption as well. The functional role of the CA IV isozyme in this process remains to be established. CA IV could be coupled to the cytosolic CA I and CA II in the $\mathrm{CO}_{2}$-stimulated uptake of sodium and chloride by catalyzing the regeneration of $\mathrm{CO}_{2}$ from excreted $\mathrm{H}^{+}$and $\mathrm{HCO}_{3}^{-}$at the luminal surface. This would provide addi- 

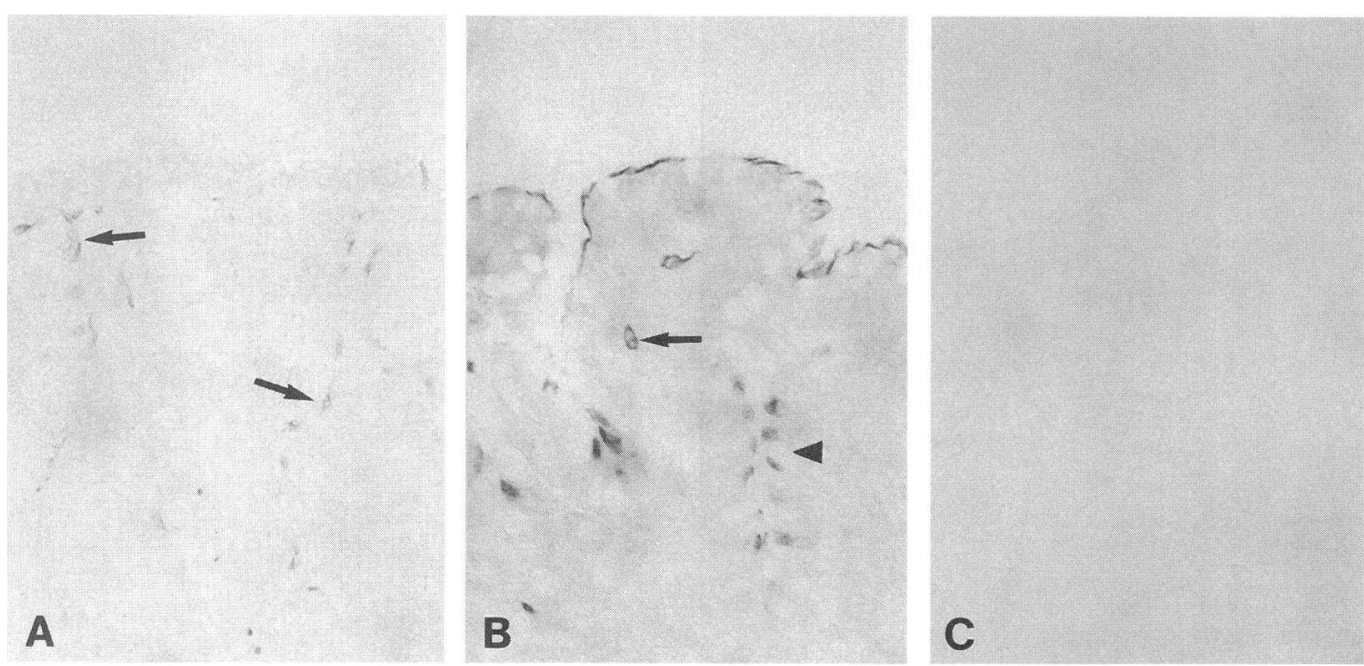

Figure 5. Immunoperoxidase staining of CA IV in the human stomach and colon. In the stomach $(A)$ signal is confined to the subepithelial capillary endothelium. In colon $(B)$ signal appears in the apical plasma membrane of the nongoblet epithelial cells of the colon, in addition to the capillary endothelium (arrows). No immunostaining is present in the goblet cells (arrowheads). Control section of the human colon remained unstained when nonimmune rabbit serum was used in place of CA IV antisera $(C)$. Original magnifications: $\times 360$.

tional $\mathrm{CO}_{2}$ to further stimulate absorption of sodium chloride (and water).

The observation that CA IV expression in the gut does not parallel that of the cytosolic CAs suggests alternative (or additional) roles for CA IV uncoupled to cytosolic activity. It has been hypothesized that membrane-associated CA activity in the intestine participates in absorption of short chain fatty acids $(27,28)$. In the proposed model, luminal CA catalyzes hydration of $\mathrm{CO}_{2}$. The released hydrogen ion protonates short chain fatty acids, to permit undissociated traversion across the mucosa. Absorption of short chain fatty acids would thus lead to bicarbonate accumulation, a rise in $\mathrm{pH}$, and a fall in $\mathrm{pCO}_{2}$. Supporting this model, luminal $\mathrm{pH}$ rises but $\mathrm{pCO}_{2}$ falls during absorption of acetate in the large intestine (30). Additionally, CA IV may participate in intestinal bicarbonate transport, in a mechanism similar to that seen in the nephron. In the rat kidney, CA IV is expressed on the brush border of the proximal convoluted tubule and thick ascending limb (29). The absorption of bicarbonate in these regions depends upon the dehydration of $\mathrm{HCO}_{3}^{-}$to $\mathrm{CO}_{2}$ catalyzed by CA IV $(23,24)$.

The existence of at least three CAs in the colonic epithelium-CA I and II in the cytosol and CA IV on the plasma membrane - makes it difficult to define the individual roles for each. Macromolecular CA inhibitors, such as Prontosil-dextran (31), which can selectively inhibit the extracellular CA on the plasma membrane, may be useful for defining the role of CA IV in the gut. Such impermeant inhibitors have been used to distinguish the activities of intracellular and extracellular CAs in lung $(31,32)$ and muscle $(33)$. Studying the effects of such inhibitors on ion transport on inverted gut segments, where acetazolamide has been shown to inhibit sodium and chloride transport $(24,25,26)$ should provide information on the role of CA IV in this process. The phenotypes of inherited enzyme deficiencies offer another potential means of defining the contributions of specific CA isozymes. The absence of gastrointestinal symptoms in CA II-deficient human patients, for example, suggests that CA I can provide the needed intracellular catalytic activity in colon $(34,35)$. No heritable deficiencies of CA IV have been identified to date. Ultimately, disruption of genes for specific CA isozymes in transgenic animals may offer the best approach to identifying the individual roles of CA I, II, and IV in the gastrointestinal tract.

In addition to expression in the intestinal epithelium, CA IV is also expressed in the submucosal capillary endothelium. This capillary expression was found even in segments without immunodetectable protein in the epithelium. Other capillary beds expressing CA IV include the pulmonary alveolar capillaries (10), the choriocapillaris of the eye (11), peripheral cortical capillaries in brain (12), and microcapillaries in skeletal and cardiac muscle (13). These capillary beds serve tissues in which $\mathrm{CO}_{2}$ flux is high. Removal of $\mathrm{CO}_{2}$ generated by tissue metabolism is presumably facilitated by CA IV on the endothelial surface to hydrate the $\mathrm{CO}_{2}$ to $\mathrm{HCO}_{3}^{-}$and $\mathrm{H}^{+}$, or conversely in the lung, to dehydrate $\mathrm{HCO}_{3}^{-}$to $\mathrm{CO}_{2}$ for elimination.

The immunohistochemical studies of human colon and stomach indicate that the observations made in the rat are relevant to human biology. One may speculate that injury to the brush border in the colon may disrupt CA IV-mediated processes, and contribute to disease pathogenesis. If, for example, the proposed role for CA IV in colonic salt and water absorption is correct, loss of CA IV activity might contribute to the pathogenesis of diarrheal conditions.

\section{Acknowledgments}

Appreciation is expressed to Catherine Stolle for the rat CA II cDNA, Jiyan Ma for the murine CA I cDNA, Joni Theobald for technical assistance, and Tealjoy Stephens for manuscript preparation.

This work was supported by grants from the National Institutes of Health (GM-34182 and DK-40163) to W. S. Sly and a grant from the Fleur de Lis Foundation to R. E. Fleming.

\section{References}

1. Tashian, R. E. 1989. The carbonic anhydrases: widening perspectives on their evolution, expression and function. Bioessays. 10:186-192.

2. Deutsch, H. F. 1987. Carbonic anhydrases. Int. J. Biochem. 19:101-113. 
3. Zhu, X. L., and W. S. Sly. 1990. Carbonic anhydrase IV from human lung: Purification, characterization and comparison with membrane carbonic anhydrase from human kidney. J. Biol. Chem. 265:8795-8801.

4. Storey, B. T., S. J. Dodgson, and R. E. Forster II. 1984. Mitochondria carbonic anhydrase: the purified enzyme. Ann. N.Y. Acad. Sci. USA. 429:210211.

5. Murakami, H., and W. S. Sly. 1987. Purification and characterization of human salivary carbonic anhydrase. J. Biol. Chem. 262:1382-1388.

6. Alfred, P., P. Fu, G. Barrett, J. D. Penschow, R. D. Wright, J. P. Coghlan, and R. T. Fernley. 1991. Human secreted carbonic anhydrase: cDNA cloning, nucleotide sequence, and hybridization histochemistry. Biochemistry. 30:569575.

7. Whitney, P. L., and T. C. Briggle. 1982. Membrane-associated carbonic anhydrase purified from bovine lung. J. Biol. Chem. 257:12056-12059.

8. Wistrand, P. J., and K. D. Knuuttila. 1989. Renal membrane-bound carbonic anhydrase. Purification and properties. Kidney Int. 35:851-859.

9. Waheed, A., X. L. Zhu, and W. S. Sly. 1992. Membrane-associated carbonic anhydrase from rat lung: Purification, characterization, tissue distribution, and comparison with CA IVs of other mammals. J. Biol. Chem. 267:3308-3311.

10. Fleming, R. E., E. C. Crouch, C. A. Ruzicka, and W. S. Sly. 1993 Pulmonary carbonic anhydrase IV: developmental regulation and cell-specific expression in the alveolar capillary endothelium. Am. J. Physiol. 265:L627-L635.

11. Hageman, G. S., X. L. Zhu, A. Waheed, and W. S. Sly. 1991. Localization of carbonic anhydrase IV in a specific capillary bed of the human eye. Proc. Natl. Acad. Sci. USA 88:2716-2720.

12. Ghandour, M. S., O. K. Langley, X. L. Zhu, A. Waheed, W. S. Sly. 1992 Carbonic anhydrase IV on brain capillary endothelial cells: A marker associated with the blood-brain barrier. Proc. Natl. Acad. Sci. USA 89:6823-6827.

13. Waheed, A., X. L. Zhu, W. S. Sly, P. Wetzel, and G. Gros. 1992. Rat skeletal muscle membrane associated carbonic anhydrase is $39 \mathrm{kDa}$ glycosylated GPI-anchored CA IV. Arch. Biochem. Biophys. 294:550-556

14. Peterson, G. L. 1977. A simplification of the protein assay method of Lowry et al. which is more generally applicable. Anal. Biochem. 83:346-356.

15. Maren, T. H. 1960. A simplified micromethod for the determination of carbonic anhydrase and its inhibitors. J. Pharmacol. Exp. Ther. 130:26-29.

16. Sundaram, V., P. Rumbolo, J. Grubb, P. Strisciuglio, and W. S. Sly. 1986. Carbonic anhydrase II deficiency: diagnosis and carrier detection using differential enzyme inhibition and inactivation. Am. J. Hum. Genet. 38:125-136.

17. Parkkila, S., A.-K. Parkkila, K. Kaunisto, A. Waheed, W. S. Sly, and H. Rajaniemi. 1993. Location of a membrane-bound carbonic anhydrase isozyme (CA IV) in the human male reproductive tract. J. Histochem. Cytochem. 41:751 757.

18. Stolle, C. A., M. H. McGowan, R. A. Heim, M.Varia, and J. A. Neubauer 1991. Nucleotide sequence of a cDNA encoding rat brain carbonic anhydrase II and its deduced amino acid sequence. Gene. 109:265-267.

19. Fraser, P. J., and P. J. Curtis. 1986. Molecular evolution of the carbonic anhydrase genes: calculation of divergence time for mouse carbonic anhydrase I and II. J. Mol. Evol. 23:294-299.

20. Lonnerholm, G. O. Selking and P. J. Wistrand. 1985. Amount and distribution of carbonic anhydrase CA I and CA II in the gastrointestinal tract. Gastroenterology. 88:1151-1161.

21. Knickelbein, R. P. S. Aronson, C. M. Schron, J. Seifter, and J. W. Dobbins 1985. Sodium and chloride transport across rabbit ileal brush border. II. Evidence for $\mathrm{Cl}-\mathrm{HCO}_{3}$ exchange and mechanism of coupling. Am. J. Physiol. 249:G236246.

22. Fraser P., P. Cummings, and P. Curtis. 1989. The mouse carbonic anhydrase I gene contains two tissue-specific promoters. Mol. Cell. Biol. 9:3308-3313.

23. Turnberg, L. A., F. A. Bieberdorf, S. G. Morawski, and J. S. Fordtran. 1970. Interrelationships of chloride, bicarbonate, sodium, and hydrogen transport in the human ileum. J. Clin. Invest. 49:557-567.

24. Charney, A. N., and G. M. Feldman. 1984. Systemic acid base disorders and intestinal electrolyte transport. Am. J. Physiol. 247:G1-G12.

25. Binder, H. J., E. S. Foster, M. E. Budinger, and J. P. Hayslett. 1987. Mechanism of electroneutral sodium chloride absorption in distal colon of the rat. Gastroenterology. 93:449-455.

26. Dagher, P. C., R. W. Egnor, and A. N. Charney. 1993. Effect of intracellular acidification on colonic $\mathrm{NaCl}$ absorption. Am. J. Physiol. 264:G569-G575.

27. Ruppin, H., S. Bar-Meir, K. H. Soergel, C. M. Wood, and M. G. Schmitt. 1980. Absorption of short chain fatty acids by the colon. Gastroenterology. 78:1500-1507.

28. Argenzio, R. A., M. Southworth, J. E. Lowe, and C. E. Stevens. 1977. Interrelationship of $\mathrm{Na}, \mathrm{HCO}_{3}$ and volatile fatty acid transport by equine large intestine. Am. J. Physiol. 233:E469-E478.

29. Brown, D., X. L. Zhu, and W. S. Sly, 1990. Localization of membraneassociated carbonic anhydrase type IV in kidney epithelial cells. Proc. Natl. Acad. Sci. USA. 87:7457-7461.

30. Argenzio, R. A., and S. C. Whipp. 1979. Interrelationship of sodium, chloride, bicarbonate and acetate transport by the colon of the pig. J. Physiol. 295:315-381.

31. Heming, T. A., C. Geers, G. Gros, A. Bidani, and E. D. Crandall. 1986. Effects of dextran-bound inhibitors on carbonic anhydrase activity in isolated rat lungs. J. Appl. Physiol. 61:1849-1856.

32. Effros, R. M., L. Shapiro, and P. Silverman. 1980. Carbonic anhydrase activity of rabbit lungs. J. Appl. Physiol. 49:589-600.

33. Geers, C., G. Gros, and A. Gartner. 1988. Extracellular carbonic anhydrase of skeletal muscle associated with the sarcolemmal. J. Appl. Physiol. 59:548558.

34. Sly, W. S., D. Hewett-Emmett, M. P. Whyte, Y.-S. L. Yu, and R. E. Tashian. 1983. Carbonic anhydrase II deficiency identified as the primary defect in the autosomal recessive syndrome of osteopetrosis with renal tubular acidosis and cerebral calcification. Proc. Natl. Acad. Sci. USA. 80:2752-2756.

35. Sly, W. S. 1989. The carbonic anhydrase II deficiency syndrome: osteoporosis with renal tubular acidosis and cerebral calcification. In The Metabolic Basis of Inherited Disease. Sixth edition. C. R. Scriver, A. L. Beaudet, W. S. Sly, and D. Valle editors. McGraw-Hill, New York. 2857-2866. 